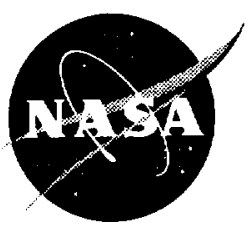

\title{
Design and Integration of a Rotor Alone Nacelle for Acoustic Fan Testing
}

Tony D. Shook, Christopher E. Hughes, William K. Thompson,

Paul F. Tavernelli, and Cameron C. Cunningham

Glenn Research Center, Cleveland, Ohio

Ashwin Shah

Sest, Inc., Middleburg Heights, Ohio

Prepared for the

39th Aerospace Sciences Meeting and Exhibit

sponsored by the American Institute of Aeronautics and Astronautics

Reno, Nevada, January 8-11, 2001

National Aeronautics and

Space Administration

Glenn Research Center 


\section{Acknowledgments}

The authors would like to thank Vic Canacci, Jose Gonsalez, Larry Heidelberg, Tony Herrmann, Gerald Hill, Gene Pinali, Paul Steve, and Sam Yunis for their significant efforts in making the design and integration of RAN possible.

Available from

NASA Center for Aerospace Information

7121 Standard Drive

Hanover, MD 21076

Price Code: A03
National Technical Information Service 5285 Port Royal Road Springfield, VA 22100 Price Code: A03 


\title{
DESIGN AND INTEGRATION OF A ROTOR ALONE NACELLE FOR ACOUSTIC FAN TESTING
}

\author{
Tony D. Shook, Christopher E. Hughes, William K. Thompson, \\ Paul F. Tavernelli, and Cameron C. Cunningham \\ National Aeronautics and Space Administration \\ Glenn Research Center \\ Cleveland, Ohio 44135 \\ Ashwin Shah \\ Sest, Inc. \\ Middleburg Heights, Ohio 44130
}

\begin{abstract}
A brief summary of the design, integration and testing of a rotor alone nacelle (RAN) in NASA Glenn's 9'x15' Low Speed Wind Tunnel (LSWT) is presented. The purpose of the RAN system was to provide an "acoustically clean" flow path within the nacelle to isolate that portion of the total engine system acoustic signature attributed to fan noise. The RAN design accomplished this by removing the stators that provided internal support to the nacelle. In its place, two external struts mounted to a two-axis positioning table located behind the tunnel wall provided the support. Nacelle-mounted lasers and a closed-loop control system provided the input to the table to maintain nacelle to fan concentricity as thermal and thrust loads displaced the strut-mounted fan. This unique design required extensive analysis and verification testing to ensure the safety of the fan model, propulsion simulator drive rig, and facility, along with experimental consistency of acoustic data obtained while using the RAN system. Initial testing was used to optimize the positioning system and resulted in concentricity errors of \pm 0.0031 inches in the horizontal direction and $+0.0035 /-0.0013$ inches in the vertical direction. As a result of successful testing, the RAN system will be transitioned into other acoustic research programs at NASA Glenn Research Center.
\end{abstract}

\section{Background}

In recent years, NASA has aggressively studied the noise characteristics of the fan bypass stage in modern turbofan engines. The objective was to better understand and thus mitigate aircraft engine noise near airports. Previous wind tunnel testing identified potential noise reduction concepts that contributed significantly to the successful achievement of the aggressive milestones in NASA's aircraft noise reduction programs. However, further investigation of the noise generating mechanisms in turbofan engines was needed if additional noise reduction was to be achieved. The knowledge gained would lend itself to developing novel technologies targeted at specific noise areas. As a result, an experimental program called the Source Diagnostic Test (SDT) was initiated to investigate these noise generating mechanisms associated with turbofan engines in the area of fan broadband noise. The investigation was carried out in the acoustically treated NASA Glenn 9'x15' LSWT using the Ultra High Bypass (UHB) fan drive rig (Fig. 1), an air turbine driven propulsion simulator. The test article was a $1 / 5$-scale model of a current generation high-bypass turbofan engine.

The RAN project, part of the SDT test program, called for the development of an "acoustically clean" flow path within the nacelle. Specifically, the internal exit guide vanes, stators, or mounting struts that contributed to the engine system acoustic signature needed to be removed. Previous acoustic research has identified that a primary source of broadband noise in a turbofan engine is the fan wake interacting with the downstream stators. By removing this fan/stator interaction through elimination of the stators, the fanonly noise signature could be characterized, and the 


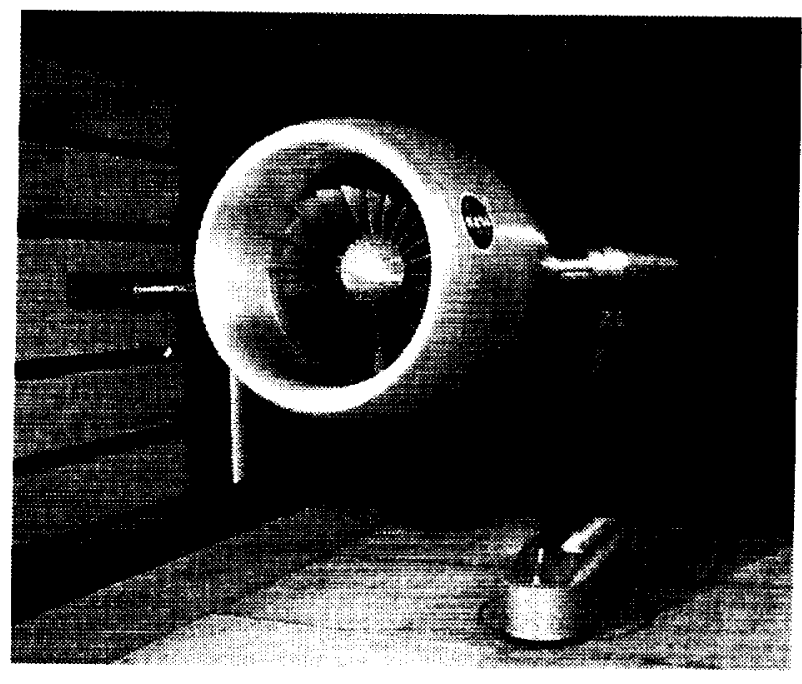

Fig. 1. Turbofan Simulation Test in NASA Glenn $9^{\prime} \times 15^{\prime}$ LSWT in Standard Acoustic Configuration

interaction noise generating mechanism could be better defined. However, for this engine model, the stators provided the only nacelle support to the UHB drive rig. The only means of achieving such an 'acoustically clean' design was to decouple the nacelle from the model centerbody. This required the nacelle to be externally mounted, independent of the fan and UHB drive rig.

The designers of the RAN system were faced with significant challenges due to the acoustic research requirements. The primary design challenge was to maintain an "acoustically clean" environment by providing external nacelle support that would not contaminate the acoustic environment. The nacelle support structure could not intrude into the model flow path nor create any noise reflecting surfaces that the acoustic microphones would record. In addition, the support structure design could not create any noise caused by air flowing over the structure.

Another major challenge facing the RAN design team was the requirement to maintain tight concentricity between the fan and nacelle during testing to ensure circumferentially uniform fan tip clearance and, uniform aerodynamic fan loading. The fan tip clearance was anticipated to be 0.020 inches at maximum fan testing speed of 12,746 RPM $(100.7 \%$ of corrected fan design speed). In addition, if the concentricity offset exceeded 0.005 inches (indicating that the system was not operating properly), all motion of the RAN system would be stopped. An earlier research study of fan model displacement, with a traditional stator supported nacelle, found that the fan face would pitch downward as much as 0.080 inches, yaw to one side 0.040 inches, and move forward 0.125 inches, due to thermal loads in the model and aerodynamic thrust loads introduced by the fan. During normal operation of the UHB drive rig, these displacements do not occur quickly since the fan speed changes are made gradually.

The displacements due to thermal loads were attributed mainly to heating gradients in the drive rig especially near the drive turbine, which was located on top of the drive strut and on the same shaft as the fan. Air at $450 \mathrm{psi}$ and $600^{\circ} \mathrm{F}$ was introduced to the drive turbine through the floor into the strut and the turbine plenum, causing high local heating. The oil for the shaft bearings operates at a cooler $250^{\circ} \mathrm{F}$, which kept the internal drive rig temperatures at that level. Additional thermal gradients arose from relatively low turbine exit temperatures and the external convective cooling of the entire test structure produced by the wind tunnel and fan air flows over the drive rig. This combination of sources and sinks generates large thermal gradients that result in non-repeatable rig deformations with fan speed. A passive displacement system, one that would control the position of the nacelle with respect to the fan, was deemed risky due to the inconsistent rig displacements. Considering all these factors, an active control system was necessary for RAN based on the positioning requirements during testing.

\section{System Description}

As stated earlier, the design goal of RAN was to operate at a fan speed of 12,746 corrected rpm while maintaining concentricity within 0.005 inches and a fan tip clearance with the nacelle of 0.020 inches. A twostrut configuration was selected to support the nacelle externally, extending horizontally from the nacelle to the test section wall (Fig. 2). A nacelle support system with two thin struts was selected over a single thick strut of equal rigidity to help minimize the acoustic disturbance of the support. In addition, the struts were positioned on the opposite side of the nacelle with respect to the acoustic microphones, so that they were in the "shadow" of the nacelle and therefore acoustically invisible. To further reduce any chance of acoustic impact, aerodynamic leading and trailing edges were added to the struts (Fig. 3). These struts also provided an ideal means for routing hundreds of instrumentation, electric and cooling lines to the model.

The positioning table was mounted outside the tunnel wall to minimize the flow field disturbances (Figs. 2 and 11). The positioning table provided movement in both the horizontal and vertical directions. Position correction in the axial direction was not required since the outer flow path around the fan was 


\section{FRONT VIEW}

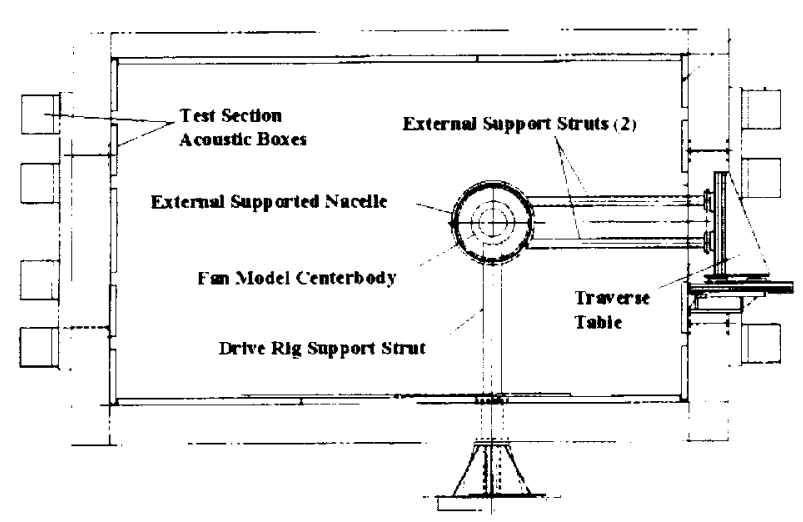

\section{TOP VIEW}

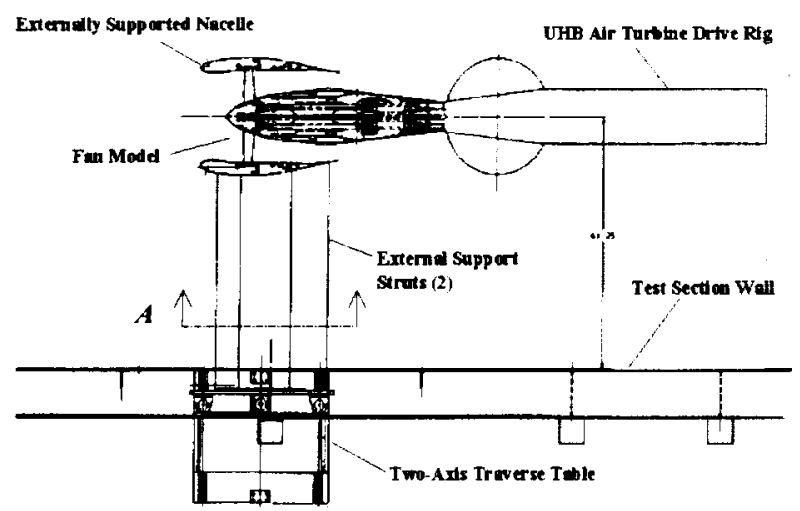

Fig. 2. Front and Top View of RAN Configuration for 9' $x$ 15' LSWT

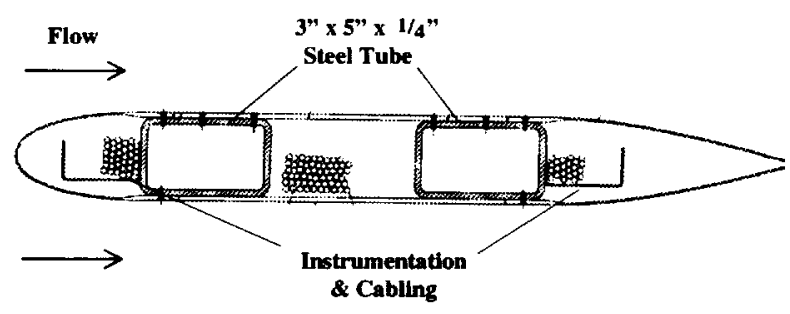

Fig. 3. Cross-section of Nacelle Support Strut (Section A-A from Fig. 2)

nearly constant in diameter, and therefore, any fan motion in this direction would not impact concentricity or tip clearance. The positioning table design was optimized for rigidity (2" thick steel plate construction), accuracy $(0.0002 " /$ inch of travel), and repeatability $(0.0002 ")$. Each table rode on bearings and rails that were selected to maximize stiffness. A five horsepower servomotor with a 100:1 gearbox drives a zero backlash, preloaded, ball screw on each axis. Four electric brakes, one on each ball screw shaft and one integral to each servomotor, were used to hold table position. Table 1 provides a summary of the RAN position control system specifics, and Fig. 4 shows the two-axis positioning table.

The feedback control system was designed for precision, redundancy, and low cost. Four laser sensors (Figs. 5, 6 and 7), mounted on the nacelle at 90-degree intervals, measured the distance from the nacelle to the center body. Two of the laser sensors, one on each axis, provide the primary feedback signals for the

\begin{tabular}{ll}
\hline Specification & Characteristics \\
\hline Drive motors & Five horsepower servomotor \\
\hline Drive control & Servo drives \\
\hline Gear mechanism & Right angle $100: 1$ gearhead \\
\hline Drive mechanism & $11 / 2$ " dia. $\times$. 50 lead rolled ball screw (both axes) \\
\hline Rail system & Linear ball bearings with rails (both axes) \\
\hline Mechanical & Mechanical end-of-travel limit switches \\
limits & Adjustable hardstops \\
\hline Brakes: & Fail-safe (energized to release brakes) \\
Ball Screw Shaft- & 24 VDC (both axes) \\
Servomotor- & 18 VDC (both axes) \\
\hline Rated speed & 0.01 in./sec \\
\hline Allowable travel & 2 in. (both axes) \\
\hline Repeatability & 0.0002 in. (both axes) \\
\hline Position accuracy & 0.0002 in./inch of travel (both axes) \\
\hline
\end{tabular}

Table 1. RAN Positioning Table Specifications

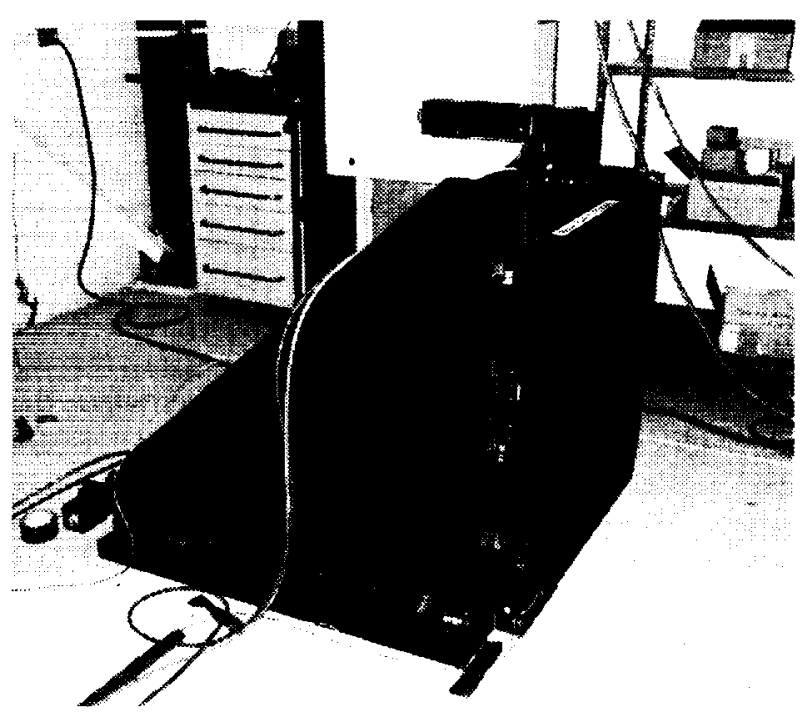

Fig. 4. Two-axis Positioning Table 
positioning table control system; the other two laser sensors were independent backups. The system was later modified during testing by averaging the laser sensor signals to allow more accurate positioning of the nacelle and reduce the positioning deadband.' Space constraints dictated that the lasers could not be mounted with the beams directed radial; consequently, both the source and scatter signals were deflected $90^{\circ}$ via polished aluminum mirrors (Fig. 5). Bench tests confirmed the validity of this approach. One inch diameter flats were machined on the centerbody as targets and were located 6.31 " from their respective mirror. Each laser sensor was enclosed in a sheet metal housing that directed a cooling gas to maintain the laser temperature below the manufacturer's limit of $120^{\circ} \mathrm{F}$; beyond this the measurement drift would lead to unacceptable position errors. The analog signals from the laser sensors were fed into a multi-purpose I/O card, as were the discrete signals for each laser sensor alarm, motor thermostats, axis faults and axis motion indicators. Discrete outputs from this card enabled motion and placed the servo drives in manual or automatic mode.

Fig. 8 shows the flowchart for the control system. The positioning table control system consisted of two servomotors, one for each axis, and their controllers. The servomotor controllers executed motion commands, tracked table position and controlled motor/shaft brakes. The controllers maintained serial communication with a STD-bus based microcomputer. The microcomputer sampled the laser sensor signals, computed the position correction required to achieve concentricity, and commanded the servomotor controllers to move the table accordingly.

The graphical user interface allowed an operator to monitor and, if needed, operate the RAN system during test activities (Fig. 9). The operator could manually move the table, activate/deactivate automatic control, monitor table position and nacelle concentricity, and "zero" table/laser positions, as well as diagnose and respond to fault conditions.

A combination of parameter constraints in the software, limit switches, and hard stops ensured that the concentricity error could not reach the point where the fan blades would come into metal-to-metal contact with the nacelle. In addition to the software and hardware safety features, a 0.67 inch thick, low-density, polyurethane foam, abradable, material was used as a rub strip over the fan blades. Based on the anticipated fan/drive rig displacement and fan tip gap during normal testing, the clearance stack-up showed a safety factor greater than 10 .

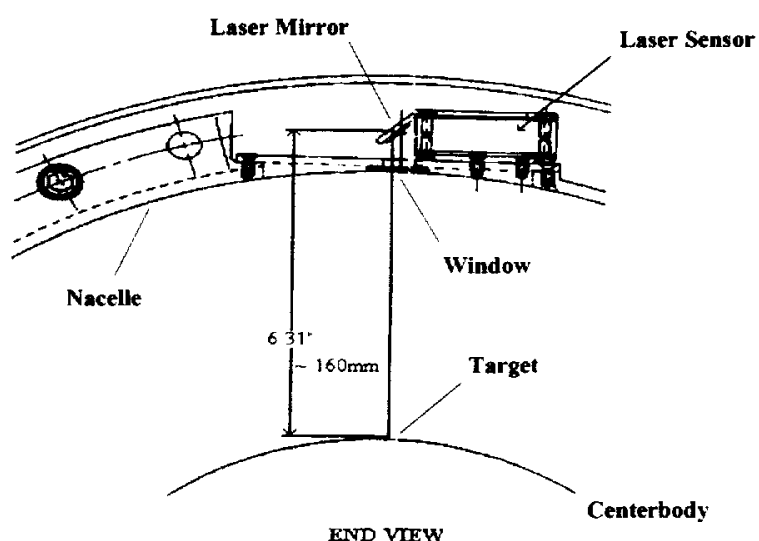

Fig. 5. Laser Displacement Sensor Schematic

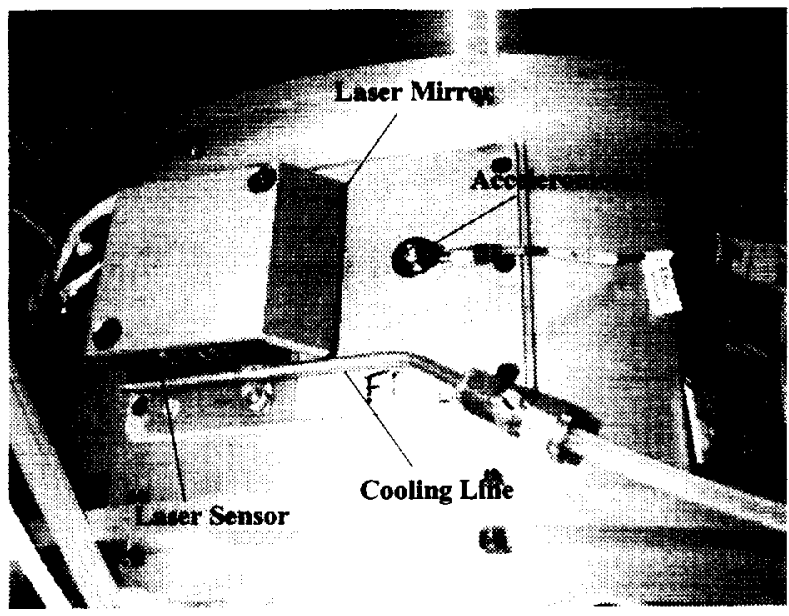

Fig. 6. Laser Displacement Sensor in RAN Assembly (w/ Thermal Housing Removed)

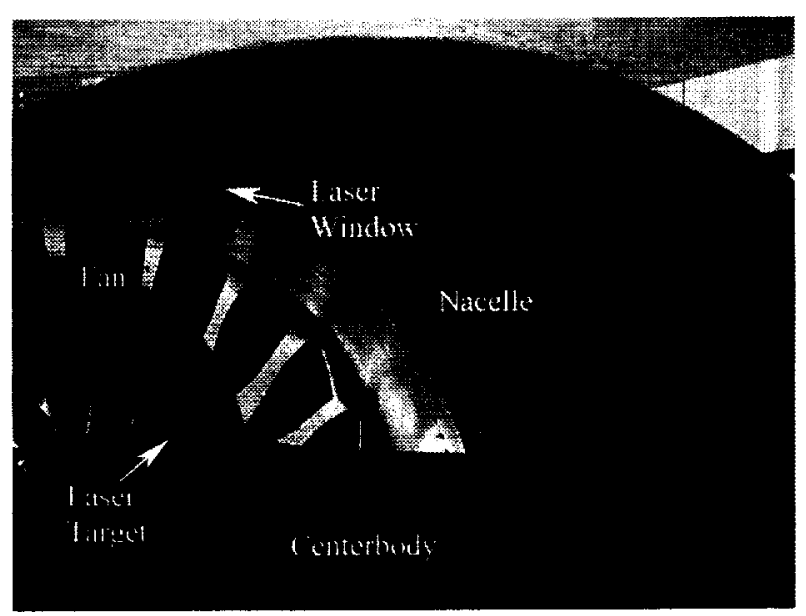

Fig. 7. Internal View of Flowpath, Aft Looking Forward 


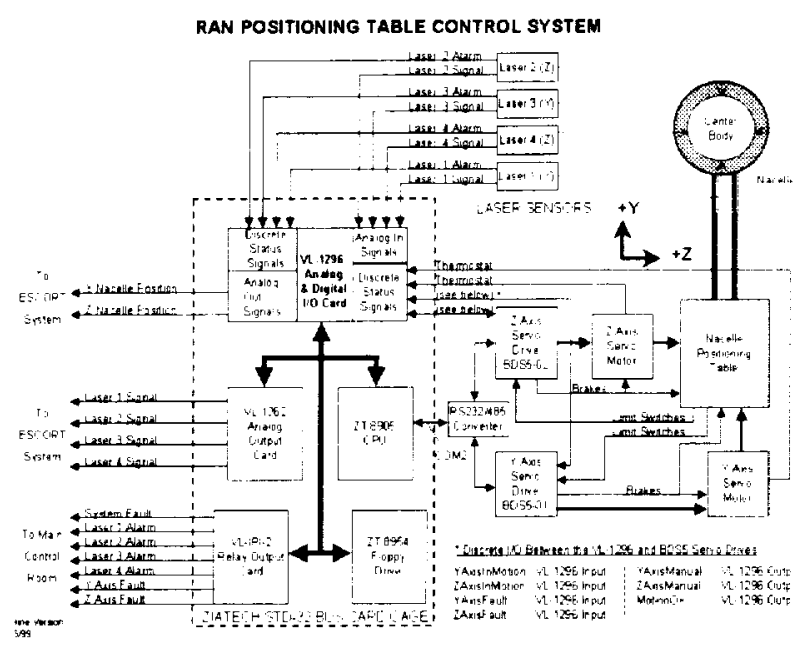

Fig 8. Control System Flowchart

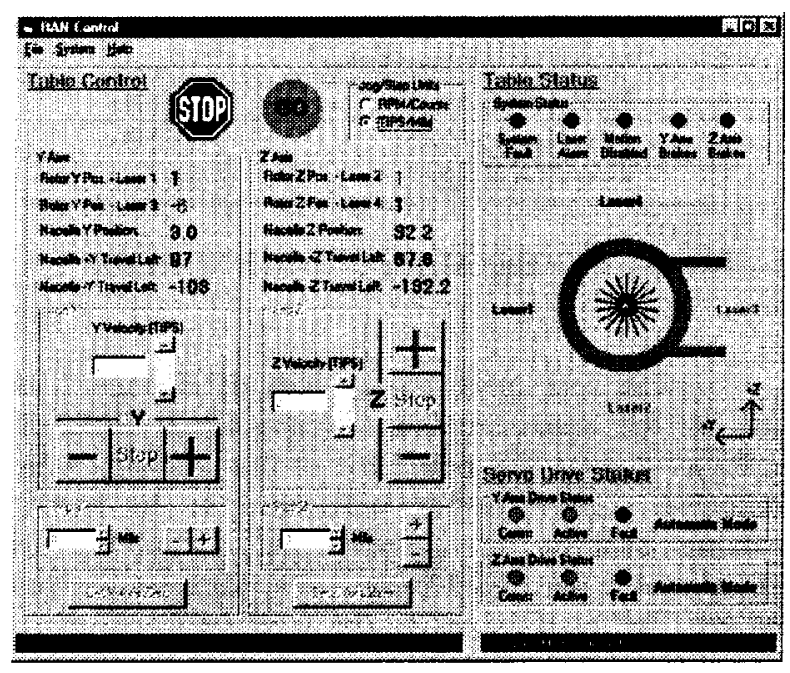

Fig. 9. Positioning Table Operator Control Interface

\section{Analysis and Verification}

An extensive analysis and verification effort was undertaken to ensure that the RAN system was structurally, dynamically and aeroelastically safe. As described earlier, the hardware was designed to accept significant incursions of the fan tips into the rub strip without damage to the fan or the rest of the model hardware. The drive rig in the 9'x15' LSWT utilized an automatic shutdown capability which was triggered whenever a facility-critical parameter, such as bearing temperature, vibration, etc., exceeded its limits. As the thrust load from the fan relieved, the drive rig would quickly displace back toward its static position. Because the positioning system was not designed to control for rapid displacements, a significant fan incursion into the rub strip was possible, and stabilizing/containing such a violent event was a critical design consideration. Consequently, low-density polyurethane foam was selected for the rub strip material. An analytical model was developed to verify the rub stability for a range of rub strip material densities (10 to $\left.40 \mathrm{lb} / \mathrm{ft}^{3}\right)$. A test apparatus and procedure was also developed to validate properties of the material used in the rub stability analysis.

Because the fan and nacelle were decoupled, each was subject to a range of dynamic and steady loads that would result in relative motion between two. Due to the independent motion of the fan blades and the nacelle, it was possible that a rub against the nacelle could cause instabilities in their relative motion. The resulting "fan bounce" could cause damage to the fan and/or unsafe conditions in the wind tunnel. Since the clearance between the fan blade tips and the rub strip was anticipated to be $0.020^{\prime \prime}$, the entire system had to be designed and analyzed very prudently. Due to the random characteristics of loads on the test structure, a probabilistic analysis of the loss of clearance was deemed necessary.

The objective of the probabilistic analysis was to analyze/design the RAN system such that the probability of exceeding the design clearance requirement of 0.020 " was minimal and the margin of safety acceptable. The entire analysis/design effort was divided into the following four main parts: (1) preparation of a detailed finite element model, as shown in Fig. 10; (2) developing a methodology to quantify the probability of exceeding the design clearance; (3) verification of the methodology; and (4) computing the probability of exceeding the clearance for the actual RAN system.

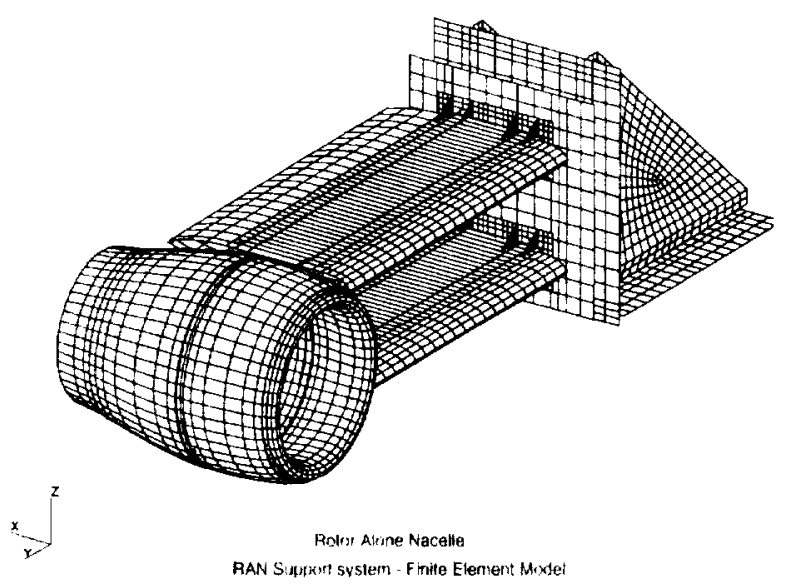

Fig. 10. Finite Element Model of the RAN System (Fan and Drive Rig not Shown) 
The finite element model included the nacelle, struts, fan drive rig, the connections between nacelle and struts, the positioning table, the connections between the positioning table and struts, and the positioning table bearings. A probabilistic methodology was developed and consisted of: (1) computing the frequency domain random loads (power spectral density [PSD] functions), (2) performing the random vibration analysis, (3) quantification of the probability of loss of clearance using barrier crossing analysis. ${ }^{2}$ To verify the methodology, a single strut typical of the design used in the RAN system was mounted to the tunnel wall without a nacelle and fan to determine the flow induced vibrations and its dynamic response. The methodology was applied to a finite element model of the strut and the computed dynamic characteristics were compared with those from the tests. The experimentally extracted damping was used in the analysis. A comparison of the free vibration analysis results with the test data (Table 2) shows excellent correlation. The mode shape correlation is given in Table 3, and is considered good when the diagonal terms are between 0.9 and 1.0 and the off-diagonal terms are between 0.0 and 0.1 . The first two modes are all in or near these ranges. However, the correlation for the third mode (torsional) and its related off-diagonal terms are not as close as expected, mainly due to insufficient instrumentation required to capture the torsional effect. The torsional mode was not expected to contribute significantly to the loss of clearance due to its high frequency; it was computed mainly to verify that the first two modes of vibration contained $99 \%$ of the energy. To provide further confidence in the model, the computed accelerations of the struts at different locations were compared with those from the test data. The experimental and analytical results, as well as their trends, compared well, which provided confidence in the methodology used. A full report of the comparison of this acceleration data has been omitted for brevity.

\begin{tabular}{ccccc}
\hline Mode & $\begin{array}{c}\text { Test } \\
\text { Frequency } \\
\text { (Hz) }\end{array}$ & $\begin{array}{c}\text { Correlated } \\
\text { Frequency } \\
\text { (IDEAS) }\end{array}$ & $\begin{array}{c}\text { Analysis } \\
\text { Frequency } \\
\text { (Nastran) }\end{array}$ & Description \\
\hline 1 & 19.92 & 20.11 & 19.48 & Out-of-plane bending \\
\hline 2 & 60.44 & 57.54 & 56.3 & In-plane bending \\
\hline 3 & 135.0 & 133.2 & 131.0 & $2^{\text {nd }}$ Out-of-plane \\
\hline
\end{tabular}

Table 2. Dynamic Frequency Correlation for Struts

The experimentally verified strut design, as described above, was used in the RAN support system. Random loads, determined from hot-wire anemometer data taken on a previous model turbofan simulation test in the 9'x15' LSWT under a steady-state flowfield at Mach 0.1 and atmospheric pressure, were converted into the PSD functions using IDEAS computer code. A random vibration analysis of the RAN system was performed using MSC/NASTRAN computer code. ${ }^{3}$ Table 4 shows the first five free vibration modes with the main component reacting in parenthesis.

\begin{tabular}{cccc}
\hline Test Modes & \multicolumn{3}{c}{ Analytical Modes } \\
\hline & $\mathbf{1}$ & $\mathbf{2}$ & $\mathbf{3}$ \\
\hline 1 & 0.90 & 0.07 & 0.41 \\
\hline 2 & 0.04 & 0.98 & 0.03 \\
\hline 3 & 0.12 & 0.05 & 0.83 \\
\hline
\end{tabular}

Table 3. Structural Dynamic Modal Correlation

\begin{tabular}{clc}
\hline Mode & Description & Frequency \\
\hline 1 & Beam Bending (struts) & $25.4 \mathrm{~Hz}$ \\
\hline 2 & Chordwise Bending (struts) & $43.6 \mathrm{~Hz}$ \\
\hline 3 & Beam Torsion (struts) & $73.2 \mathrm{~Hz}$ \\
\hline 4 & Plate Bending (table) & $83.2 \mathrm{~Hz}$ \\
\hline 5 & Plate Torsion (table) & $86.7 \mathrm{~Hz}$ \\
\hline
\end{tabular}

Table 4. Principle Modes of System Vibration

The root mean square loss of clearance, as well as the auto correlation functions at different locations around the periphery of the nacelle, were computed. These results were used in the barrier crossing analysis to quantify the probability of exceeding the loss of clearance. The analysis showed that the likelihood of losing the 0.020 inch clearance during a typical two hour test was 62 out of 100,000 .

Divergence and flutter analysis of the RAN system was performed to verify the stability under aeroelastic conditions at Mach 0.2. Although the test condition would not exceed 0.1 Mach, the stability verification up to 0.2 Mach provided additional margin of safety. Aerodynamic analyses based on both the Double-Lattice Subsonic Lifting surface and VortexLattice theory revealed that the system does not diverge up to $0.2 \mathrm{Mach}^{4}$ The flutter analysis using the PK method showed that the system has enough structural and aerodynamic damping to absorb the aerodynamic loads up to $181 \mathrm{~Hz}$ vibration frequencies and shows no sign of flutter. ${ }^{5}$ Since the system was not expected to respond beyond $181 \mathrm{~Hz}$ frequencies, the flutter analysis for higher modes was deemed unnecessary. Thus, the RAN support system was found to be stable with regard to divergence and flutter up to Mach 0.2. 


\section{Hardware Checkout and Installation}

Prior to installation in the $9^{\prime} \times 15^{\circ}$ LSWT, a comprehensive checkout of RAN positioning system was completed. The RAN traverse table was floormounted and qualified with the same hardware that would be used in the wind tunnel (Fig. 11). The target centerbody ( $\mathrm{w} /$ machined flats) was mounted to a controllable two-axis traverse system (Probe Actuator Control System, or PACS) that provided motion with a resolution of 0.001 inches, allowing the RAN system response to be compared against known inputs. Checks included manual and automatic operability, sampling rate, vibrational response, and failure modes. Since the main design goals of the RAN system was to prevent a fan rub into the casing, the checkout was conducted with verification of fail-safe operation as the principle objective. However, this checkout could not simulate the operating temperatures, excitation, facility noise, and aerodynamic effects found in the LSWT; followon verification testing was needed. At this point, the RAN system was ready for tunnel installation.

Modifications to the wind tunnel were required to support the positioning table and maintain the acoustic environment of the tunnel test section. By mounting the positioning table behind the tunnel wall, the table and its support structure caused negligible changes to the acoustic environment. The tunnel wall that supports the positioning table was stiffened with additional beams (Fig. 12). A platform was constructed to support the positioning table, and was secured to both the tunnel sidewall structure and ground for maximum rigidity. Accurate alignment of the nacelle with the drive rig fan was critical for this test. Proper flow-fields would not be created if the position of the nacelle and fan drive rig were not accurately maintained. The axial location of the positioning table was set to a reference surface on the drive rig, while horizontal and vertical alignment was obtained by shimming the positioning table. Final concentricity of the fan and the nacelle was achieved by "jogging" the two-axis positioning table. New acoustic boxes were fabricated to accommodate the positioning table and support struts (Figs. 12 and 13). These acoustic boxes maintained a uniform aeroacoustic environment around the new RAN support hardware.

\section{Integrated System Performance}

During initial testing, the excitation level of the nacelle was closely monitored, but never exceeded the noise floor of the accelerometers. A post-run impact test confirmed that the RAN system was highly damped. On the first $100 \%$ speed test, a fan rub of about 0.020 inches occurred. An alternate configuration using a fixed nacelle supported by stators was used to measure fan tip clearance. This test data

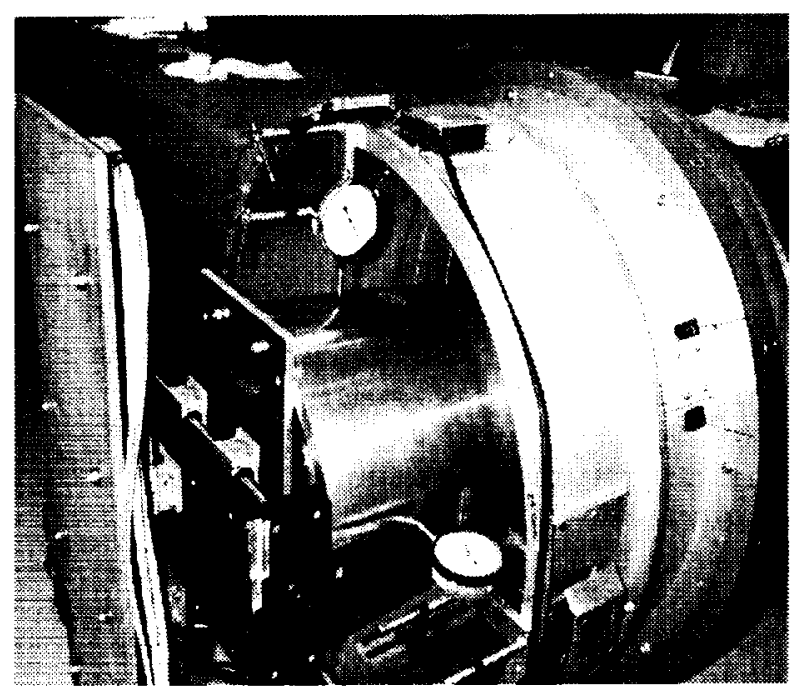

Fig. 11. Checkout of RAN w/PACS Traverse

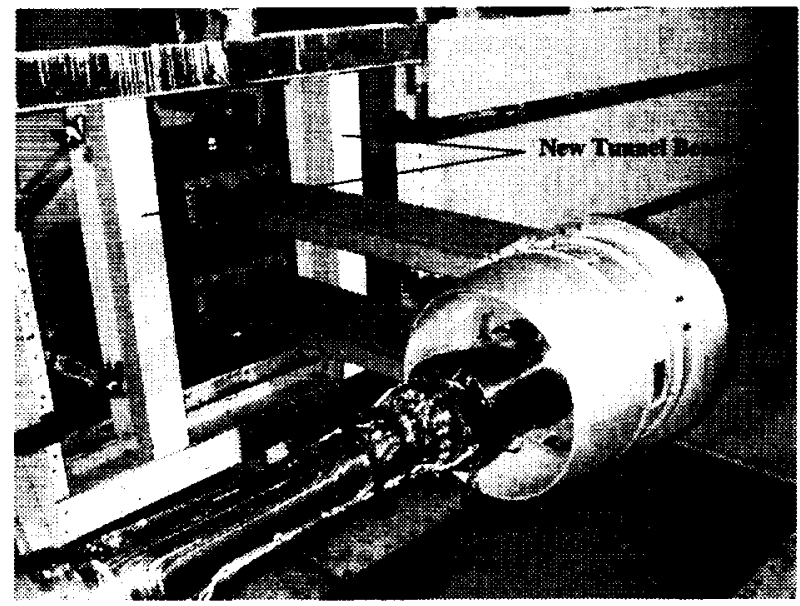

Fig. 12. Wind Tunnel Modifications for RAN Installation

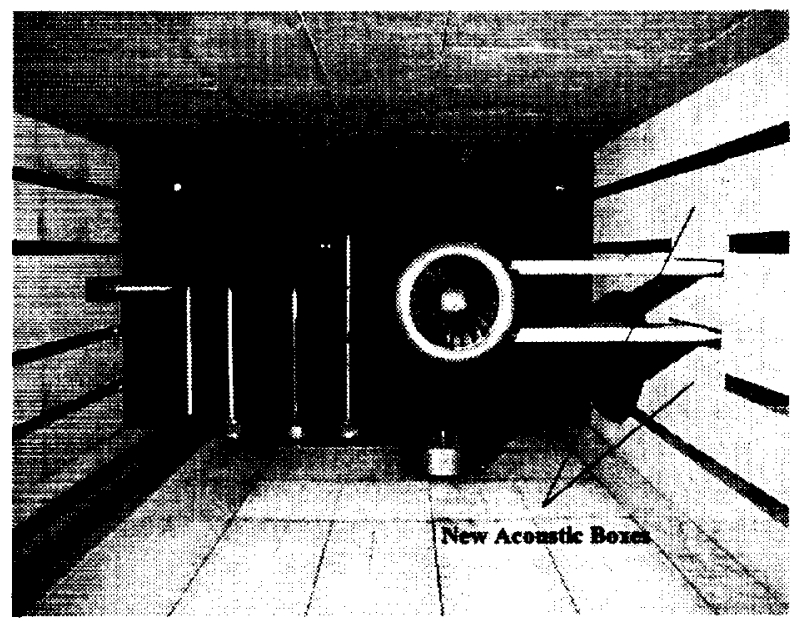

Fig. 13. Front View of RAN Hardware in LSWT 
revealed clearance of 0.004 inches at the fan leading edge, not 0.020 inches as originally predicted. Consequently, modifications were needed to improve centering performance and decrease the positioning deadband.

Thermal drift in the laser sensor readings was the major contributor to displacement error; therefore, a three-pronged approach was utilized to counteract drift. First, the laser cooling system was improved by increasing the coolant flow rate and chilling the coolant fluid, lowering the temperature at the laser head by approximately $30^{\circ} \mathrm{F}$. Second, the amount of error introduced by the thermal drift effect was calculated from opposing lasers and subtracted from the control readings. Third, startup and centering procedures were developed to reduce relative drift. In addition, instrumentation filters and improved averaging provided excellent noise immunity.

The performance gains from optimization were significant enough to reduce the deadband to 0.0015 inches. Analysis revealed concentricity errors in the horizontal direction and vertical direction of 0.0032 inches and $0.0036 /-0.0014$ inches, respectively. A full description of the optimization of RAN, along with the concentricity analysis, can be found in Ref. 1 . Table 5 summarizes the characteristics of RAN before and after optimization.

\begin{tabular}{lll}
\hline Characteristic & Final & Initial \\
\hline Resolution of Motion & 0.0001 in. & 0.0001 in. \\
\hline Sampling Rate & $1 \mathrm{~Hz}$ & $2 \mathrm{~Hz}$ \\
\hline Deadband & $0.0015 \mathrm{in}$. & $0.0040 \mathrm{in}$. \\
\hline Total Runs (all speeds) & 25 & 1 \\
\hline Total Run Time & $>50$ hours & 1 hour \\
\hline Runs w/ no rubs @1 $100 \% \mathrm{~N}_{\mathrm{c}}$ & 14 & 0 \\
\hline Concentricity Error (Horiz) & \pm 0.0032 in. & $\simeq \pm 0.025 \mathrm{in}$. \\
\hline Concentricity Error (Vert) & $+0.0036 /-0.0014$ in. & $\simeq \pm 0.025 \mathrm{in}$. \\
\hline
\end{tabular}

Table 5. RAN Performance Summary

\section{Conclusions}

The Rotor Alone Nacelle (RAN) system was a unique design that allowed the acoustic testing of an isolated fan within the nacelle of a modem turbofan model in the NASA Glenn 9'x15' Low Speed Wind Tunnel. Prior characterization of the fan and drive rig motion showed that displacement was not predictable enough to exclude an active nacelle positioning control system; the data from the RAN project strongly supported this finding. The RAN system can maintain relative position of a decoupled nacelle with respect to an operating fan with high accuracy and precision. As a result, extremely tight tip clearances can be maintained for moderate ramp rates of fan speed.

The RAN system met or exceeded all design requirements and verified the feasibility of independent fan and nacelle testing. Baseline testing showed no appreciable increase in broadband noise due to the RAN hardware and tunnel modifications. Aerodynamically, the uniformity of the flow path generated by the RAN system allowed the researchers to gather dynamic pressure data with confidence in its quality. The robust mechanical design of the RAN system proved to be structurally rigid, vibrationally benign, and aeroelastically stable. The RAN system displayed excellent reliability and consistency throughout the program, and was deemed acoustically, aerodynamically, and mechanically successful.

The successes of the RAN project will enable its application in future NASA research programs. Recently, a design was completed that integrates a third axis that corrects for axial displacement of the fan and drive rig. Future testing using the RAN system will also include improvements to the laser sensor thermal control system to reduce the sensor positioning error due to thermal loads. In addition, a data recording system will be installed to log laser sensor outputs and sensor operating temperatures at both steady and transient operating speeds.

\section{References}

1. Cunningham, C.C., Thompson, W.K., and Hughes, C.E., "Performance Optimization of a Rotor Alone Nacelle for Acoustic Fan Testing", AIAA 2001-0164, Jan. 2001.

2. Newland, D.E., "An Introduction to Random Vibration and Spectral Analysis", Longman Group Limited, London.

\section{MSC/NASTRAN User's Guide, Version 69, The MacNeal-Scwendler Corporation.}

4. Albano, E., and Rodden, W.P., "A Double-Lattice Method for Calculating Lift Distributions on Oscillating Surfaces in Subsonic Flows", AIAA Journal, Feb. 1969, Vol. 7, No. 2, pp. 279-285.

5. "Modal Flutter Analysis Study; Vol. IV, Aero-ServoElastic Stability Analysis Program: PASES", Report No. SDI5204R, Hughes Aircraft Co. 

Public reporting burden for this collection of information is estimated to average 1 hour per response, including the time for reviewing instructions, searching existing data sources, gathering and maintaining the data needed, and completing and reviewing the collection of information. Send comments regarding this burden estimate or any other aspect of this Davis Highway, Suite 1204, Arlington, VA 22202-4302, and to the Otfice of Management and Buds Seves, Disectorate tor Intomalion Operations and Reports, 1215 Jefferso Davis Highway, Suite 1204, Arlington, VA 22202-4302, and to the Office of Management and Budget, Paperwork Reduction Project (0704-0188), Washington, DC 20503.

\begin{tabular}{|l|c|r|r|}
\hline 1. AGENCYUSE ONLY (Leave blank) & $\begin{array}{r}\text { 2. REPORT DATE } \\
\text { April } 2001\end{array}$ & $\begin{array}{r}\text { 3. REPOAT TYPE AND DATES COVERED } \\
\text { Technical Memorandum }\end{array}$ \\
\hline
\end{tabular}

4. TITLE AND SUBTITLE

Design and Integration of a Rotor Alone Nacelle for Acoustic Fan Testing

6. AUTHOR(S)

WU-781-13-01-00

Tony D. Shook, Christopher E. Hughes, William K. Thompson,

Paul F. Tavernelli, Cameron C. Cunningham, and Ashwin Shah

7. PERFORMING ORGANIZATION NAME(S) AND ADDRESS(ES)

National Aeronautics and Space Administration

John H. Glenn Research Center at Lewis Field

Cleveland, Ohio 44135-3191

5. FUNDING NUMBERS

10. SPONSORING/MONITORING AGENCY REPORT NUMBER

National Aeronautics and Space Administration

Washington, DC 20546-0001

NASA TM-2001-210820

AIAA-2001-1058

11. SUPPLEMENTARY NOTES

Prepared for the 39th Aerospace Sciences Meeting and Exhibit sponsored by the American Institute of Aeronautics and Astronautics, Reno, Nevada, January 8-11, 2001. Tony D. Shook, Christopher E. Hughes, William K. Thompson, Paul F. Tavernelli, and Cameron C. Cunningham, NASA Glenn Research Center; and Ashwin Shah, Sest, Inc., Middleburg Heights, Ohio 44130. Responsible person, Tony D. Shook, organization code 7725, 216-433-6373.

\begin{tabular}{|l|l|}
\hline 12a. DISTRIBUTIONAVAILABILITY STATEMENT & 12b. DISTRIBUTION CODE \\
Unclassified - Unlimited & Distribution: Nonstandard \\
Subject Categories: $07,09,33$, and $37 \quad$ & \\
Available electronically at hitp://gltrs.grc.nasa.gov/GLTRS \\
This publication is available from the NASA Center for AeroSpace Information, 301-621-0390. & \\
\hline 13. ABSTRACT (Max/mum 200 words) &
\end{tabular}

A brief summary of the design, integration and testing of a rotor alone nacelle (RAN) in NASA Glenn's 9' $\times 15$ ' Low Speed Wind Tunnel (LSWT) is presented. The purpose of the RAN system was to provide an "acoustically clean" flow path within the nacelle to isolate that portion of the total engine system acoustic signature attributed to fan noise. The RAN design accomplished this by removing the stators that provided internal support to the nacelle. In its place, two external struts mounted to a two-axis positioning table located behind the tunnel wall provided the support. Nacelle-mounted lasers and a closed-loop control system provided the input to the table to maintain nacelle to fan concentricity as thermal and thrust loads displaced the strut-mounted fan. This unique design required extensive analysis and verification testing to ensure the safety of the fan model, propulsion simulator drive rig, and facility, along with experimental consistency of acoustic data obtained while using the RAN system. Initial testing was used to optimize the positioning system and resulted in concentricity errors of $\pm 0.0031 \mathrm{in}$. in the horizontal direction and $+0.0035 /-0.0013 \mathrm{in}$. in the vertical direction. As a result of successful testing, the RAN system will be transitioned into other acoustic research programs at NASA Glenn Research Center.

\begin{tabular}{|c|c|c|}
\hline \multicolumn{3}{|l|}{ 14. SUBJECT TERMS } \\
\hline \multicolumn{3}{|c|}{$\begin{array}{l}\text { Rotor blades; Turbomachinery; Fan; Wind tunnel models; } \\
\text { Active control; Nacelles; Acoustics }\end{array}$} \\
\hline $\begin{array}{l}\text { 17. SECURITY CLASSIFICATION } \\
\text { OF REPORT }\end{array}$ & $\begin{array}{l}\text { 18. SECUAITY CLASSIFICATION } \\
\text { OF THIS PAGE }\end{array}$ & $\begin{array}{l}\text { 19. SECURITY CLASSIFICATION } \\
\text { OF ABSTRACT }\end{array}$ \\
\hline Unclassified & Unclassified & Unclassified \\
\hline
\end{tabular}

